\title{
DYNAMIC SOIL-STRUCTURE INTERACTION ANALYSIS OF A TELESCOPE AT THE JAVALAMBRE ASTROPHYSICAL OBSERVATORY
}

\author{
Stijn François ${ }^{1}$, Pedro Galvín ${ }^{2}$, Pedro Museros ${ }^{3,4}$, Geert Lombaert $^{1}$ and Geert Degrande $^{1}$ \\ ${ }^{1}$ KU Leuven, Department of Civil Engineering, Kasteelpark Arenberg 40, B-3000 Leuven, Belgium \\ ${ }^{2}$ Universidad de Sevilla, Escuela Técnica Superior de Ingenieros, Camino de los Descubrimientos, \\ 41092 Sevilla, Spain \\ ${ }^{3}$ Universitat Politècnica de Valencia, Departamento de Mecánica de Medios Continuos y Teoriá de \\ Estructuras, 46022 Valencia, Spain \\ ${ }^{4}$ Fundación Caminos de Hierro para la Investigación y la Ingenieriá Ferroviaria, C/Serrano 160, 28002 \\ Madrid, Spain \\ e-mail: stijn.francois@ bwk.kuleuven.be
}

Keywords: Dynamic soil-structure interaction, pile foundations, vibrations

\begin{abstract}
This paper reports on the dynamic soil-structure analysis of a telescope pier of an astrophysical laboratory in the Sierra de Javalambre, Teruel (Spain). Vibration control in the design stage is of prime concern, since astrophysical observations may be hindered by mechanical vibration of the sensitive optics of the telescope. These vibrations may result from wind loading on the telescope dome, transferred through the foundation to the telescope. Therefore, the manufacturer of the telescope has imposed a minimal resonance frequency of $10 \mathrm{~Hz}$ for the supporting structure. For a massive construction such as a telescope pier, this resonance frequency may be significantly influenced by the effects of dynamic soil-structure interaction; therefore the contractor company TORRESCAMARA commissioned a study with the aim of analysing such interaction effects. The telescope is mounted on a concrete pier with a height of $15.25 \mathrm{~m}$, founded on 73 reinforced concrete micro-piles with a diameter of $0.40 \mathrm{~m}$. The dynamic soil characteristics at the site have been determined by means of a down-hole test. The effect of dynamic soil-structure interaction is studied using a coupled finite element - boundary element model of the telescope pier - foundation soil system. The response of the telescope is computed for harmonic loading at the top of the telescope pier. Results demonstrate that the effect of dynamic soil-structure interaction is significant. An analysis that disregards dynamic soilstructure interaction results a predicted resonance of $14.28 \mathrm{~Hz}$ while a fully coupled analysis predicts a resonance frequency of $11.2 \mathrm{~Hz}$.
\end{abstract}




\section{INTRODUCTION}

This paper reports on the dynamic response of a telescope pier of an astrophysical laboratory in the Sierra de Javalambre, Teruel (Spain). From early in the design stage, vibration control has been of prime concern, since astrophysical observations may be hindered by mechanical vibration of the sensitive optics of the telescope. These vibrations are expected to result from wind loading on the telescope dome, transferred through the foundation to the telescope [6].

In order to avoid the mechanical vibration of the sensitive optics of the telescope, the telescope manufacturer has imposed that the resonance frequency of the telescope pier should be higher than $10 \mathrm{~Hz}$. For a massive construction such as a telescope pier, this resonance frequency may be significantly lowered by the effects of dynamic soil-structure interaction. On the other hand, dynamic soil-structure interaction allows for the dissipation of energy through wave propagation in the soil, mitigating resonance peaks.

This paper investigates the effects of dynamic soil-structure interaction on the resonance frequency of the telescope pier by means of a coupled finite element - boundary element model of the telescope pier - foundation - soil system.

The paper is outlined as follows. In section 2, the dynamic soil characteristics at the site of the Javalambre astrophysical observatory are discussed. The geometry and material properties of the structure are summarized in section 3. In section 4, the coupled finite element - boundary element model of the telescope is outlined. The response of the telescope pier is discussed in section 5, where the effect of dynamic soil-structure interaction is investigated.

\section{SITE CHARACTERIZATION}

The Javalambre astrophysical observatory is located at the top of the Pico del Buitre, 1957 $\mathrm{m}$ above sea level, close to the village of Arcos de las Salinas (Teruel, Spain).

An extensive geotechnical site characterization of the construction site has been carried out [6]. This has revealed an intense ground fracturing combined with density changes in the rock matrix up to a depth of $7 \mathrm{~m}$ (figure 1 ).

A down-hole test has been performed at the test site [2] to determine the shear wave velocity $C_{\mathrm{s}}$ and dilatational wave velocity $C_{\mathrm{p}}$ as a function of depth (table 1). The material damping ratio of the soil as a function of depth is not available from the down-hole test, and an identical value for shear and volumetric deformation $\beta_{\mathrm{s}}=\beta_{\mathrm{p}}=0.01$ will be assumed in the following. The intense fracturing of the top rock matrix has been confirmed by the down-hole test and results in low wave speeds in the top layers.

\section{GEOMETRY AND MATERIAL PROPERTIES}

The telescope is mounted on a concrete pier with a height of $15.25 \mathrm{~m}$, founded on 73 reinforced concrete micro-piles with a diameter of $0.40 \mathrm{~m}$ (figures 2 and 3 ). The upper part of the pier is a truncated cone with an outer radius of $1.4 \mathrm{~m}$ at the top and $3.5 \mathrm{~m}$ at the base. The lower part of the telescope pier consists of a concrete cylinder with a constant outer radius of $3.5 \mathrm{~m}$, reinforced with 7 radial ribs. The overall thickness of the pier is $0.6 \mathrm{~m}$.

The telescope pier is supported by a ring-shaped pile cap with an external radius of $5 \mathrm{~m}$ and an internal radius of $1.2 \mathrm{~m}$. The pile cap has a thickness of $1.5 \mathrm{~m}$. The opening in the pile cap acts as an elevator pit for the telescope lens lift.

The concrete used for the pier and the pile cap is referred to as HA-35 and has a Young's modulus $E=35 \mathrm{GPa}$, a Poisson's ratio $\nu=0.2$ and a density $\rho=2500 \mathrm{~kg} / \mathrm{m}^{2}$. For the micro-piles, a high-strength concrete HA-45 is used, with a Young's modulus $E=37.5 \mathrm{GPa}$, 


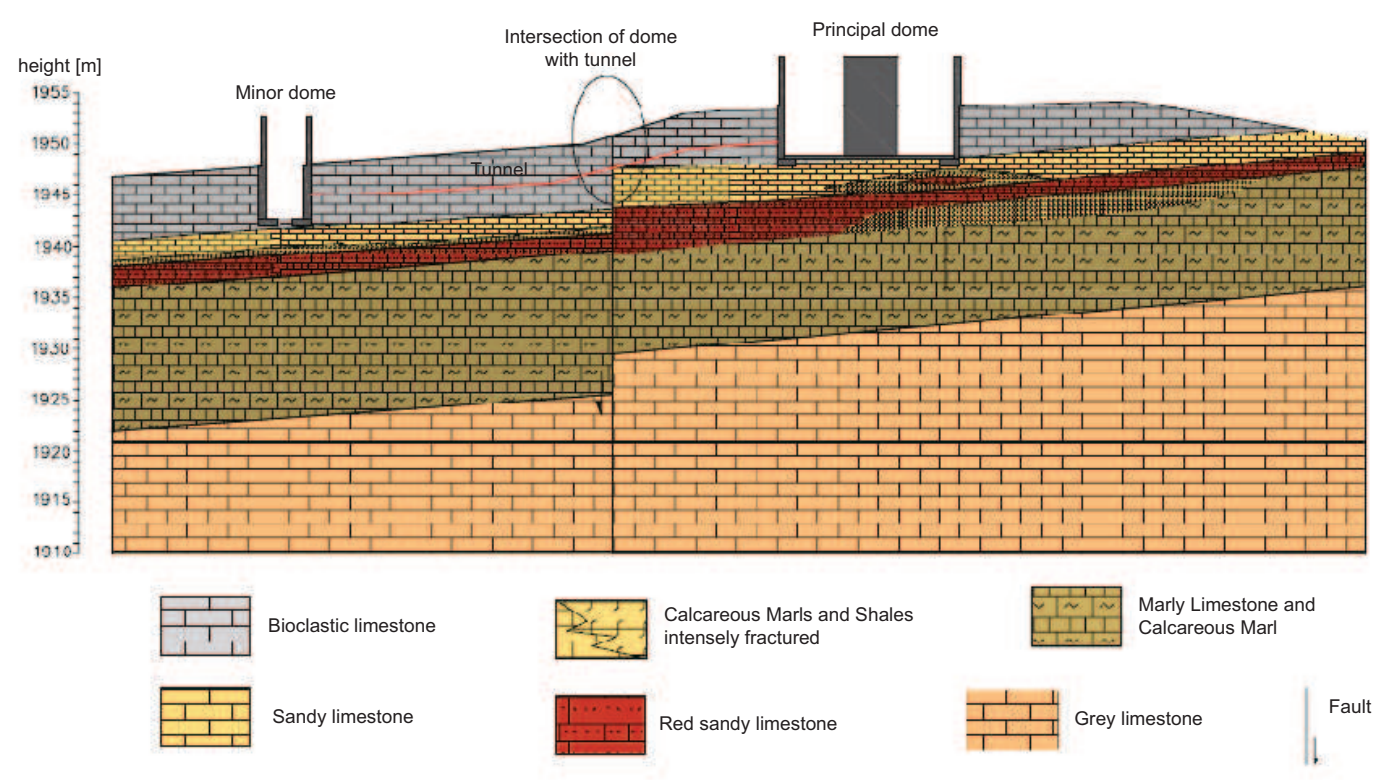

Figure 1: Geological layering at the construction site.

\begin{tabular}{|c|c|c|c|}
\hline $\begin{array}{c}\text { Depth } \\
{[\mathrm{m}]}\end{array}$ & $\begin{array}{c}C_{\mathrm{s}} \\
{[\mathrm{m}]}\end{array}$ & $\begin{array}{c}C_{\mathrm{p}} \\
{[\mathrm{m}]}\end{array}$ & $\begin{array}{c}\rho \\
{\left[\mathrm{kg} / \mathrm{m}^{3}\right]}\end{array}$ \\
\hline 1 & 407 & 646 & 2700 \\
2 & 403 & 903 & 2700 \\
3 & 446 & 937 & 2700 \\
4 & 490 & 815 & 2670 \\
5 & 520 & 937 & 2670 \\
6 & 520 & 1190 & 2250 \\
7 & 555 & 1229 & 2250 \\
8 & 974 & 3195 & 2250 \\
9 & 1056 & 3409 & 2250 \\
10 & 961 & 1811 & 2250 \\
11 & 1100 & 2335 & 2650 \\
12 & 1064 & 2670 & 2650 \\
13 & 2055 & 3335 & 2650 \\
14 & 1764 & 2647 & 2650 \\
15 & 2150 & 3164 & 2650 \\
16 & 2294 & 3759 & 2650 \\
17 & 1629 & 3505 & 2650 \\
18 & 1383 & 2635 & 2650 \\
\hline
\end{tabular}

Table 1: Dynamic soil properties at the site of the Javalambre Astrophysical Observatory.

a Poisson's ratio $\nu=0.2$ and a density $\rho=2500 \mathrm{~kg} / \mathrm{m}^{2}$. In addition, a material damping ratio $\beta_{\mathrm{c}}=0.02$ is assumed for the concrete. 


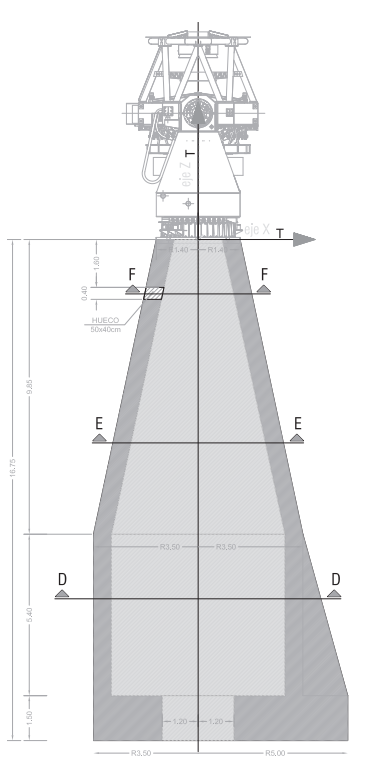

SECTION A-A

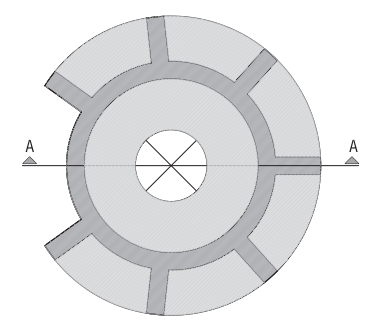

PLAN VIEW

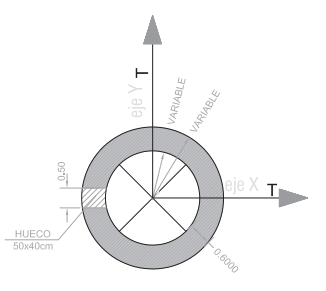

SECTION F-F

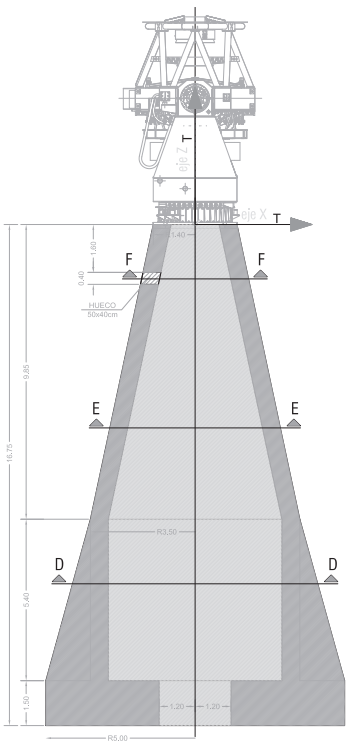

SECTION B-B

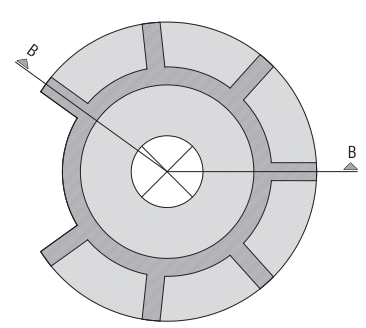

PLAN VIEW

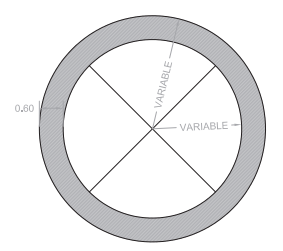

SECTION E-E

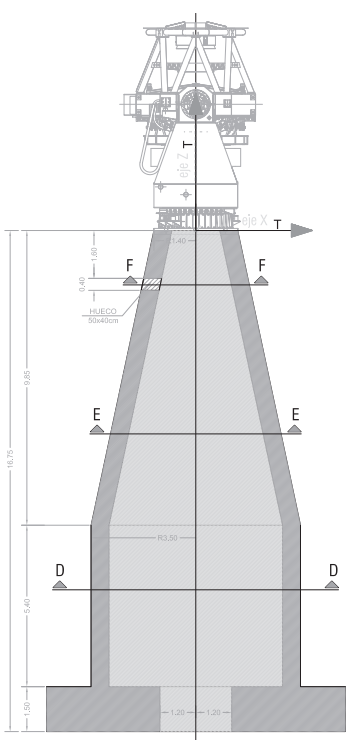

SECTION C-C

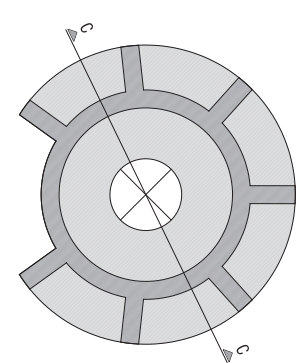

PLAN VIEW

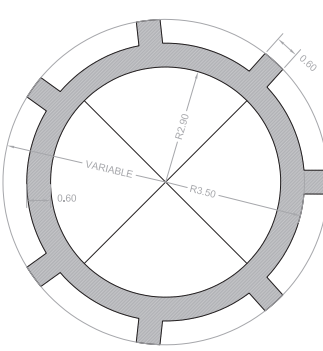

SECTION D-D

Figure 2: Layout of the telescope.

\section{NUMERICAL MODEL}

\subsection{Finite element model}

The finite element (FE) model of the telescope pier, the pile cap, the micro-piles and a cylindrical soil region with a radius of $5 \mathrm{~m}$ and a depth of $7.5 \mathrm{~m}$ is shown in figure 4. The origin of the right-handed Cartesian frame of reference $(x, y, z)$ is considered at ground level, with the $x$-axis along the center line of the notch in the pile cap and the $z$-axis ponting upwards.

The FE model is shown in figure 4. The telescope pier is meshed in Ansys with 1206 8-node rectangular shell elements with a thickness of $0.6 \mathrm{~m}$. The shell elements use Mindlin-Reissner shell theory for bending, accounting for first order shear deformation theory. The pile cap and 


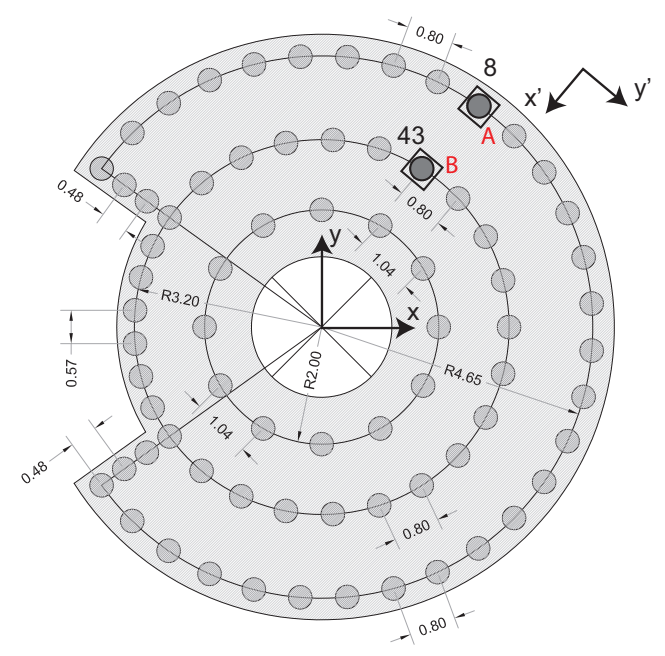

Figure 3: Layout of the pile foundation.

the cylindrical soil region are modelled with 20-node (quadratic) solid elements, employing 1720 and 3200 elements, respectively. The micro-piles are modelled with 584 beam elements, connected to the solid elements for the cylindrical soil region. The maximum element size equals $1 \mathrm{~m}$.

The telescope is represented as a rigid mass of $45000 \mathrm{~kg}$, located at a distance of $3.15 \mathrm{~m}$ above the top of the pier. This is modelled as a concentrated mass in an auxiliary node with 6 degrees of freedom at the point $(x=0, y=0, z=19.9 \mathrm{~m}$ ). Constraint equations are employed, coupling six rigid body modes of the top ring of the pier to the respective degrees of freedom of the concentrated mass.

The structure has been meshed using Ansys, whereas the Matlab toolbox StaBIL [4] is used to assemble the stiffness and mass matrices $\mathbf{K}$ and $\mathbf{M}$. The FE model (telescope pier, pile cap, pile foundation, and soil) has 25898 nodes, 6711 elements, and 90888 degrees of freedom.

\subsection{Boundary element model}

As the soil has been excavated prior to construction of the telescope, the first five soft layers in table 1 are not considered. The soil is modelled as a horizontally layered halfspace (figure 5), where the properties of the layers correspond to layers 6 to 18 of the down-hole test in table 1. The underlaying homogeneous halfspace has a shear wave velocity $C_{\mathrm{s}}=2000 \mathrm{~m} / \mathrm{s}$, a dilatational wave velocity $C_{\mathrm{p}}=3650 \mathrm{~m} / \mathrm{s}$, and a density $\rho=2650 \mathrm{~kg} / \mathrm{m}^{3}$. The latter properties are average values from a secondary down-hole test at larger depths [6].

In order to account for the interaction between the layered soil and the FE model, a boundary element (BE) model that conforms with the FE mesh of the cylindrical soil volume is employed (figure 6), where 8 -node serendipity boundary elements are used with $6 \times 6$ Gaussian integration points per element.

The BE system matrices are computed with the Matlab toolbox BEMFUN [5]. These BE system matrices allow to compute displacement and traction vectors at the BE nodes. At the edge of the bottom and side of the cylindrical soil volume, double nodes are used to account for double traction vectors on the corners. 
(a)

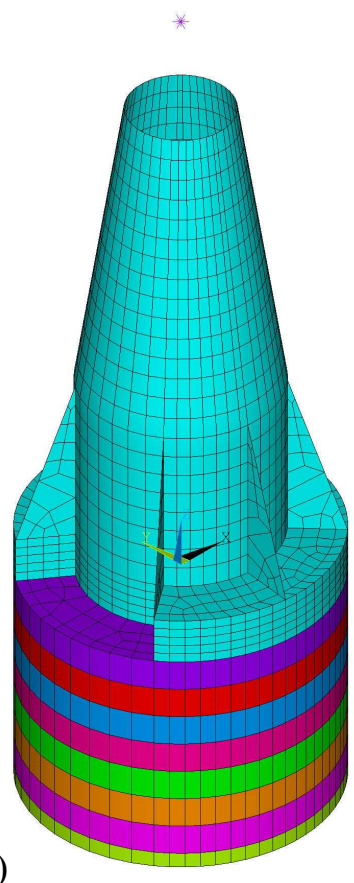

(b)

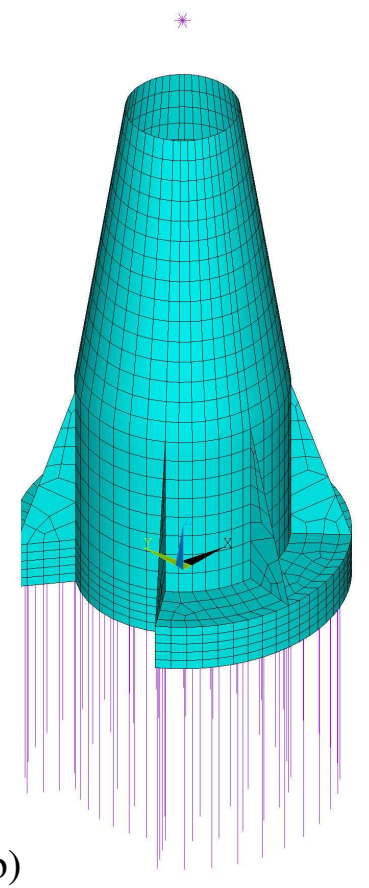

Figure 4: FE mesh of (a) the telescope pier, the pile cap, the soil and the micro-piles, and (b) the telescope pier, the pile cap, and the micro-piles. Different materials are indicated with different colors.

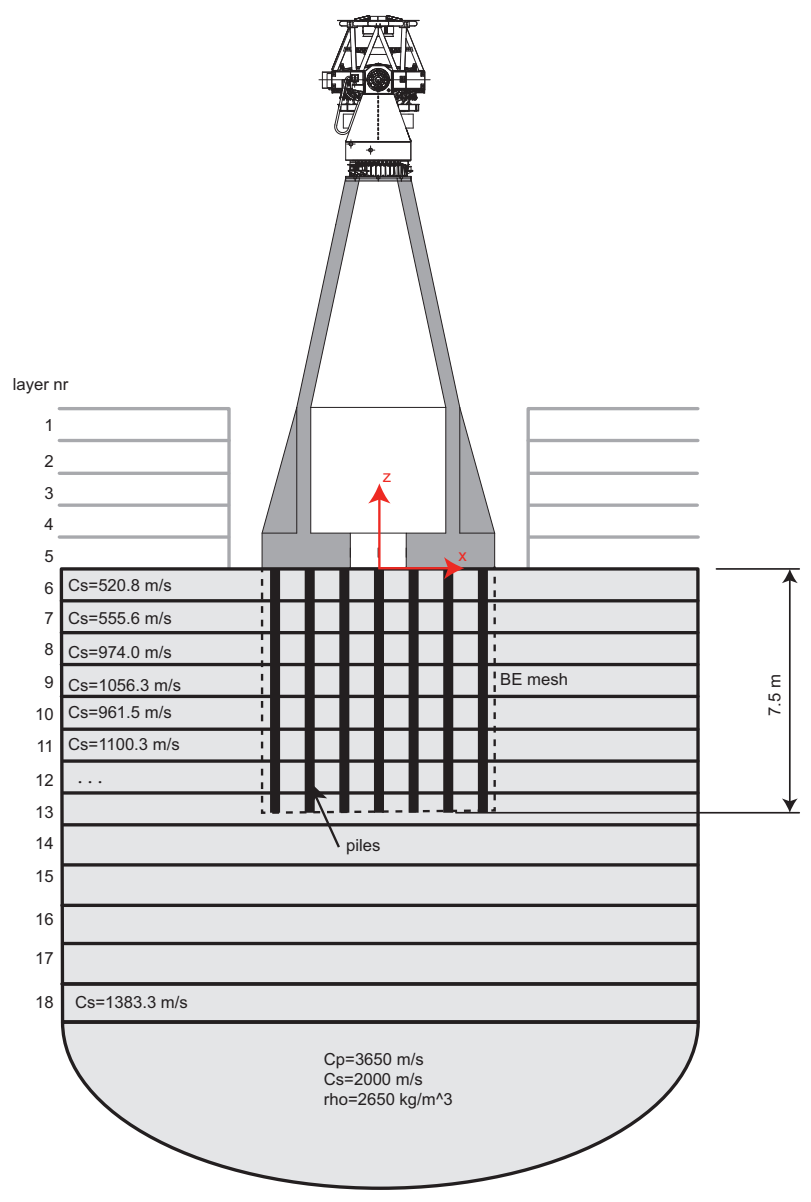

Figure 5: Layout of the coupled FE-BE model. 


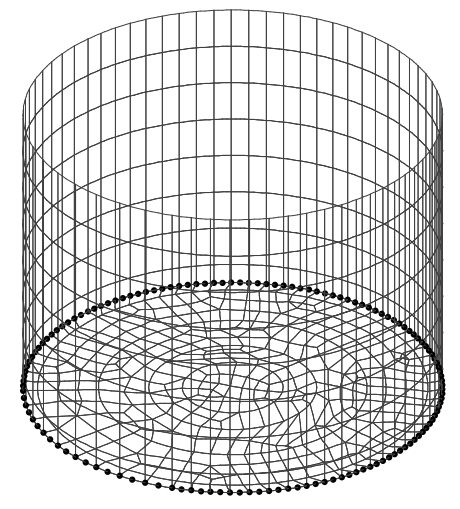

Figure 6: BE mesh conforming with the FE mesh of the cylindrical soil volume surrounding the micro-piles. The double corner nodes (black dots) are also indicated. 


\section{NUMERICAL RESULTS}

\subsection{Reference analysis disregarding dynamic soil-structure interaction}

As a reference, the response of the telescope pier fixed at the base is computed. Figure 7 shows the first 4 mode shapes. The first eigenfrequency of the structure equals $14.28 \mathrm{~Hz}$, which is well above the limit of $10 \mathrm{~Hz}$ imposed by the telescope manufacturer to avoid malfunctioning of the equipment.

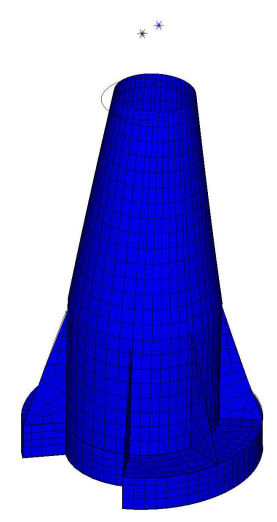

(a) Mode 1 at

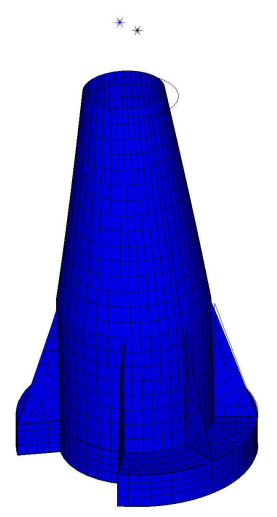

(b) Mode 2 at

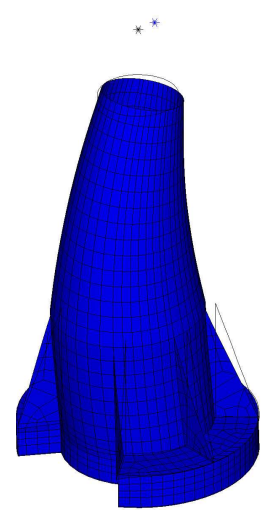

(c) Mode 3 at

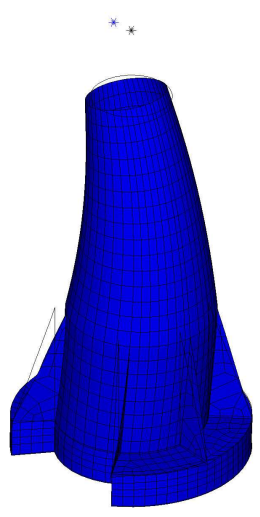

(d) Mode 4 at $42.42 \mathrm{~Hz}$

Figure 7: Eigenmodes of the structure fixed at its base.

A unit harmonic point load in the $x$-direction is applied at the concentrated mass of 45000 $\mathrm{kg}$ that represents the telescope. Figure 8 shows the displacement of the concentrated mass in the direction of the loading. The response is dominated by the first structural mode.
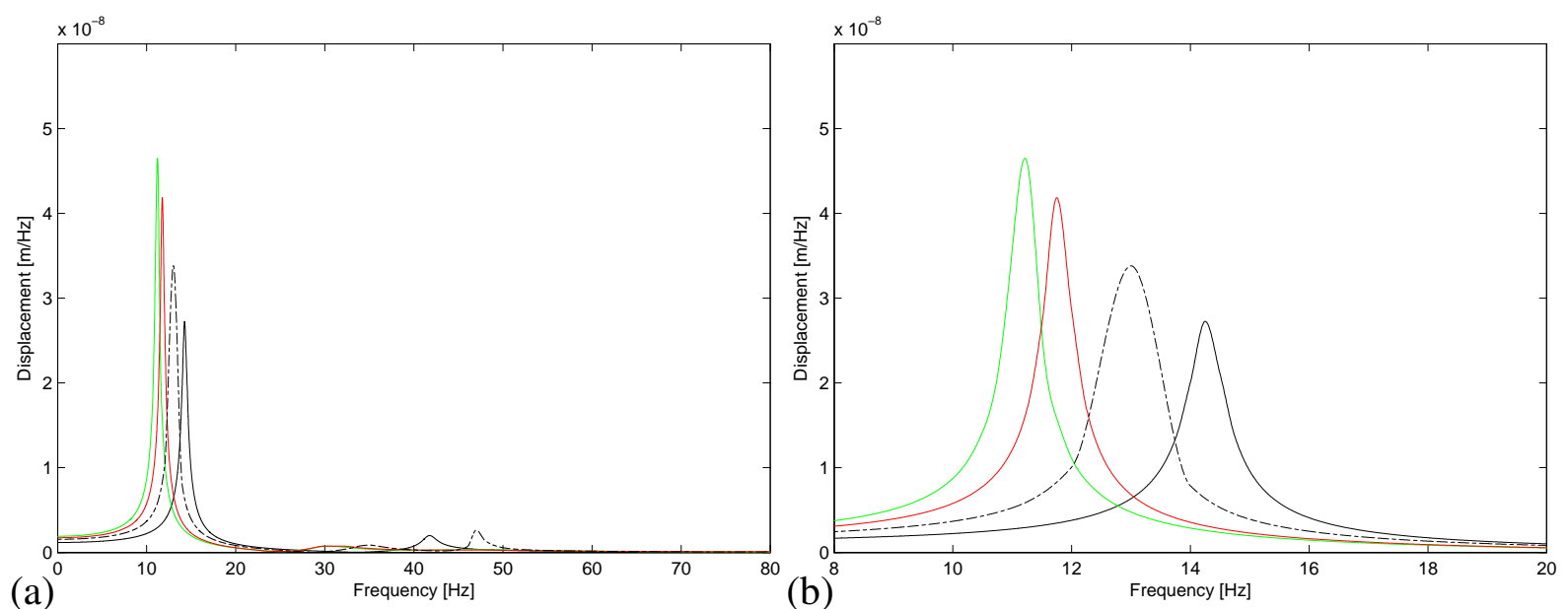

Figure 8: (a) Modulus of the displacement of the top of the telescope due to a unit harmonic horizontal load applied at the concentrated mass, and (b) zoom around the resonance peak. Results are plotted for an analysis without dynamic soil-structure interaction (solid black line), an analysis including dynamic soil-structure interaction (green line) and including dynamic soil-structure interaction with a rigid pile cap (red line) and a simplified approach (dash-dotted line). 


\subsection{Dynamic soil-structure interaction analysis}

Next, a complete dynamic soil-structure interaction analysis is performed, The response of the telescope pier due to a unit harmonic point load in the $x$-direction applied at the concentrated mass of $45000 \mathrm{~kg}$ is computed.

Figure 8 shows the displacement of the concentrated mass in the direction of the loading. The response of the telescope, loaded by a harmonic point load at the top, is dominated by a resonance peak corresponding to the first bending mode of the telescope pier. Due to the effect of dynamic soil-structure interaction, the peak response occurs at $11.2 \mathrm{~Hz}$, which is above the limit imposed by the telescope manufacturer to avoid malfunctioning of the equipment. The amplitude at the peak response is larger than the resonance frequency of the telescope pier fixed at its base, due to the lower eigenfrequency. This is partially compensated for by the additional radiation and material damping in the soil. The corresponding radiated wave field at 20, 40,60 and $80 \mathrm{~Hz}$ is plotted in figure 9 .

A modal analysis is not performed, since the presence of the soil stiffness of the layered halfspace renders the dynamic stiffness matrix frequency dependent and strongly damped.

(a)

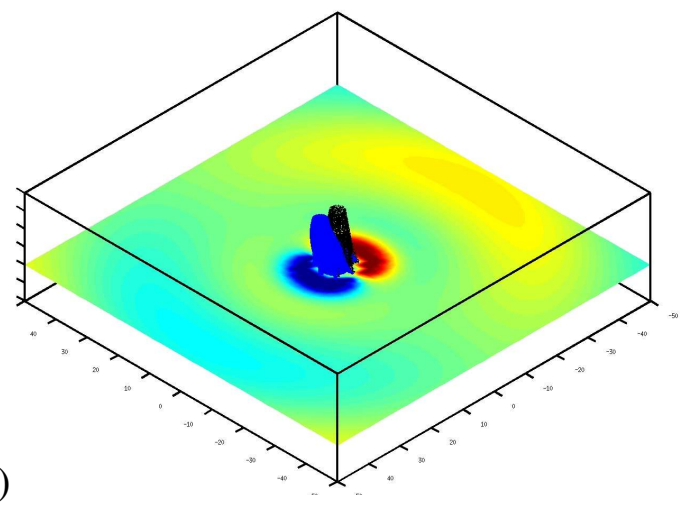

(c)

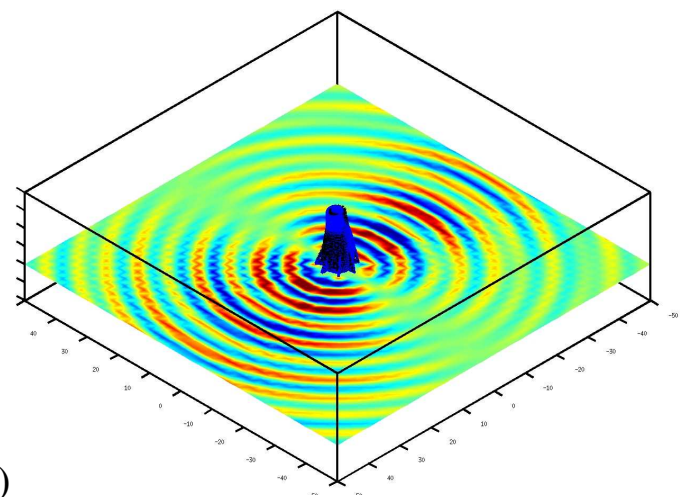

(b)

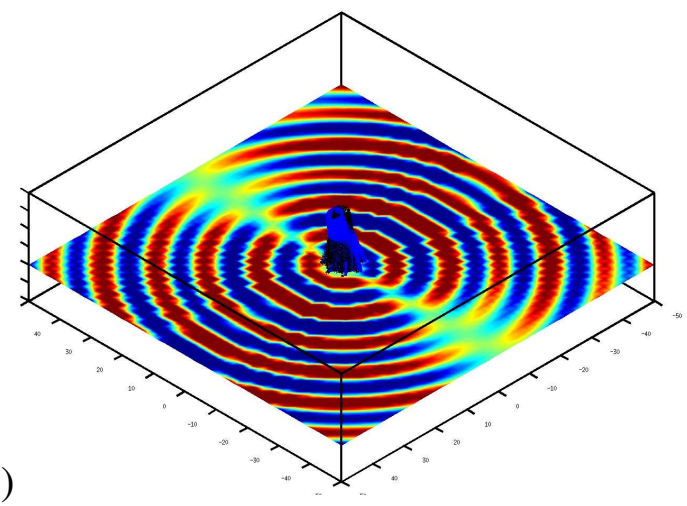

(d)

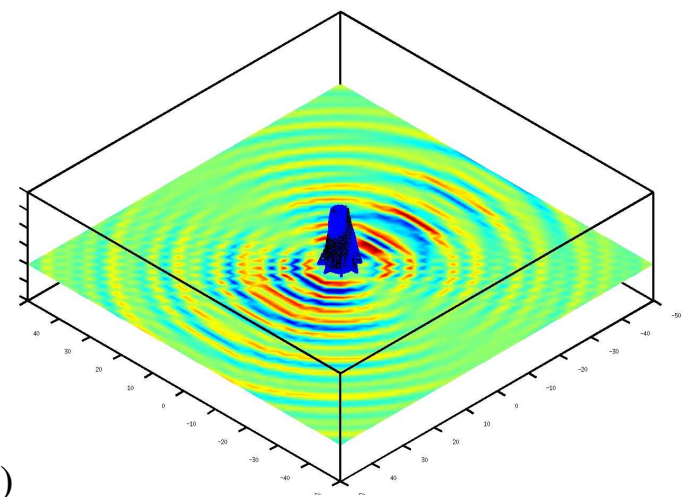

Figure 9: Real part of the vertical soil displacement at (a) $20 \mathrm{~Hz}$, (b) $40 \mathrm{~Hz}$, (c) $60 \mathrm{~Hz}$, and (d) $80 \mathrm{~Hz}$ due to a horizontal harmonic load at the top of the telescope. 


\subsection{Dynamic soil-structure interaction analysis with a rigid pile cap}

The assumption of a rigid pile cap allows the use of impedance functions [1, 3, 7] in a dynamic soil-structure interaction analysis. The frequency dependent elements $S_{m n}\left(a_{0}\right)$ of the $6 \times 6$ impedance matrix of a rigid foundation are commonly written in the following dimensionless form [7]:

$$
S_{m n}\left(a_{0}\right)=K_{m n}^{\mathrm{s}}\left[K_{m n}\left(a_{0}\right)+i C_{m n}\left(a_{0}\right)\right]
$$

where the subscripts $m$ and $n$ denote the horizontal (h), vertical (v), rotational (r) and torsional (t) degree of freedom, while the static stiffness coefficients $K_{m n}^{\mathrm{s}}$ are defined as $K_{\mathrm{hh}}^{\mathrm{s}}=K_{\mathrm{vv}}^{\mathrm{s}}=$ $\mu R, K_{\mathrm{rr}}^{\mathrm{s}}=K_{\mathrm{tt}}^{\mathrm{s}}=\mu R^{3}$ and $K_{\mathrm{hr}}^{\mathrm{s}}=\mu R^{2}$, with $\mu=C_{\mathrm{s}}^{\text {ref }} \rho$ the (reference) shear modulus of the soil. The dimensionless stiffness and damping coefficients $K_{m n}\left(a_{0}\right)$ and $C_{m n}\left(a_{0}\right)$ depend on the dimensionless frequency $a_{0}=\omega R / C_{\mathrm{s}}^{\text {ref }}$ where $R$ is the radius of the embedded cylindrical foundation.

It is noted that the imaginary part of the dynamic stiffness matrix is sometimes plotted in the literature after division by $a_{0}$. This is interesting in simple cases where the imaginary part remains more or less linear, such as for rigid surface foundations. In the case of a pile group this is not relevant and this practice is not followed in the present report.

Figure 10 shows the dimensionless stiffness and damping coefficients for the pile foundation with a rigid massless pile cap, where an average shear wave speed $C_{\mathrm{s}}^{\text {ref }}=C_{\mathrm{s}}^{\text {av }}=890 \mathrm{~m} / \mathrm{s}$ and a density $\rho=2400 \mathrm{~kg} / \mathrm{m}^{3}$ are considered to compute the dimensionless foundation characteristics.

The results are compared to results obtained with a simplified model developed by Taherzadeh et al. [8] (figure 11). Parameters are provided for floating pile groups and for end-bearing pile groups. Floating pile groups are pile groups embedded in a homogeneous halfspace while endbearing pile groups are embedded in a soft layer on top of a bedrock. Results are only given for the horizontal component $K_{\mathrm{hh}}$ and rocking component $K_{\mathrm{rr}}$ of the dynamic stiffness matrix, which dominate the response of the pile cap. The simplification consists of a lumped parameter model, composed of masses, springs and dampers. The properties of the components are determined by the parametrization:

$$
\lambda_{0}\left(\frac{R}{H}\right)^{\lambda_{1}}\left(\frac{L_{0}}{s}\right)^{\lambda_{2}}\left(\frac{\rho_{\mathrm{b}} C_{\mathrm{s}}^{\mathrm{b}}}{\rho_{\mathrm{l}} C_{\mathrm{s}}^{\mathrm{l}}}\right)^{\lambda_{3}}
$$

where $R$ is the pile cap radius, $H$ is the thickness of the top soil layer, $L_{0}=\left(E_{\mathrm{p}} I_{\mathrm{p}} / E_{l}\right)^{0.25}$ the critical pile length, $s$ the pile separation. $\rho_{\mathrm{b}}$ and $\rho_{\mathrm{l}}$ are the density of the bedrock (b) and the soil layer (1), respectively. Similarly, $C_{\mathrm{s}}^{\mathrm{b}}$ and $C_{\mathrm{s}}^{\mathrm{l}}$ are the shear wave velocities of the bedrock and the soil layer. The parameters $\lambda_{0}$ to $\lambda_{3}$ have been tuned for each of the components in the simplified model, against the results of coupled FE-BE calculations for a regular grid of piles supported by a rectangular, rigid pile cap.

The parametrization (2) reduces to the model of a floating pile group if the properties of the bedrock and the soil layer correspond $\left(\rho_{\mathrm{b}}=\rho_{\mathrm{l}}\right.$ and $\left.C_{\mathrm{s}}^{\mathrm{l}}=C_{\mathrm{s}}^{\mathrm{b}}\right)$. The model accounts for the effect of friction along the pile through the factor $\left(\rho_{\mathrm{b}} C_{\mathrm{s}}^{\mathrm{b}} /\left(\rho_{\mathrm{l}} C_{\mathrm{s}}\right)\right)^{\lambda_{3}}$, which is considered to contribute significantly to the overall vertical impedance in the present study.

Figure 10 compares the dynamic stiffness and damping coefficients obtained with both models. The correspondance is very good for the horizontal impedance at low frequencies, but deviates at higher frequencies. The rocking stiffness and damping are overestimated by the 

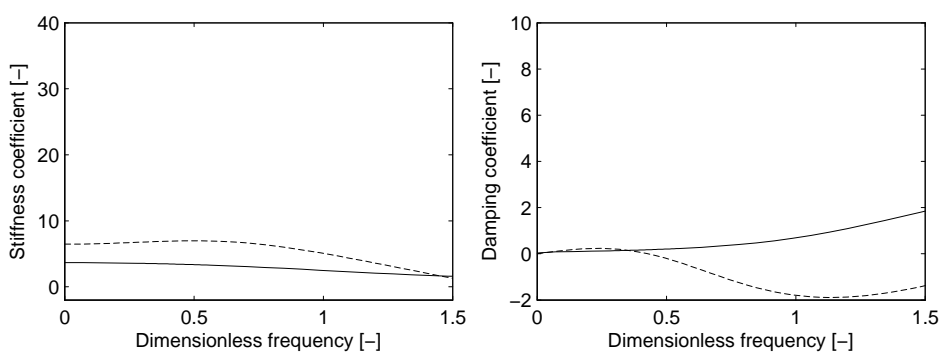

(a) $k_{\mathrm{hh}}$

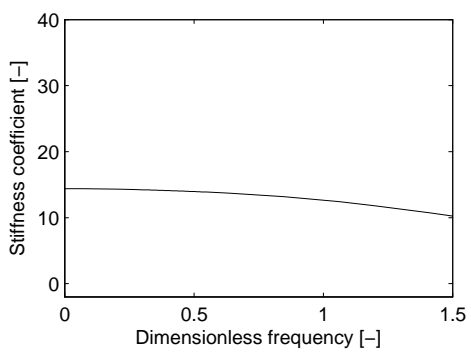

$c_{\mathrm{hh}}$

(b) $k_{\mathrm{vV}}$

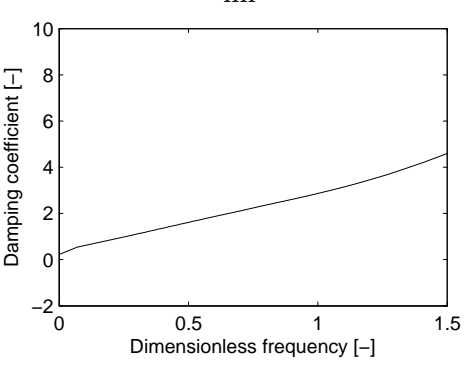

$c_{\mathrm{VV}}$
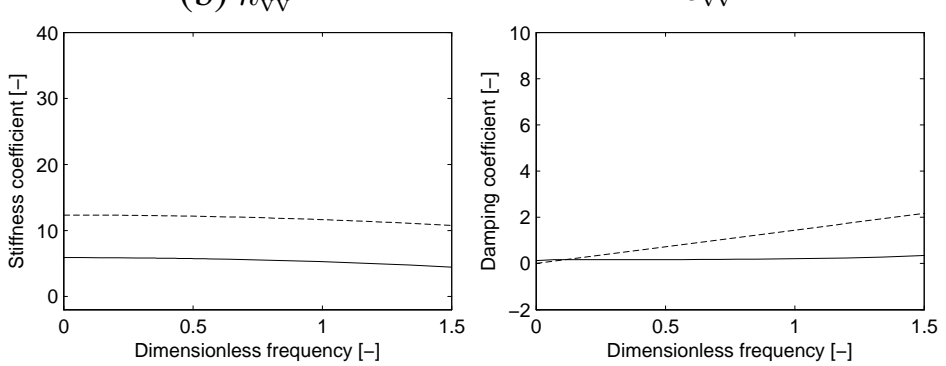

(c) $k_{\mathrm{rr}}$

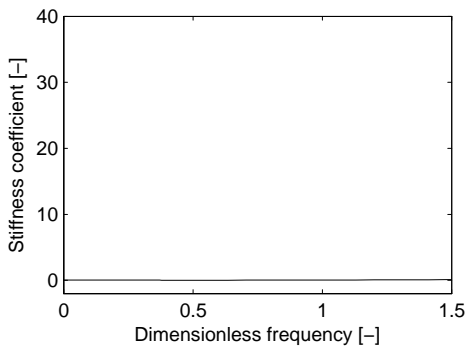

$c_{\mathrm{rr}}$

(d) $k_{\mathrm{rh}}$

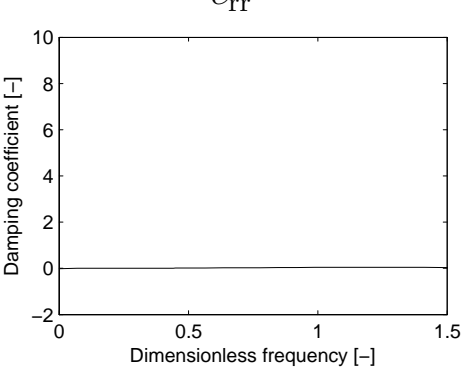

$c_{\mathrm{rh}}$

Figure 10: Stiffness (left) and damping (right) coefficients of the pile group with a rigid massless cap for the (a) horizontal, (b) vertical, (c) rocking and (d) horizontal-rocking deformation. The results obtained with the coupled FE-BE model (solid line) are compared with results obtained with a simplified model by Taherzadeh et al. [8] (dashed line) for the horizontal and rocking motion.

simplified model. This is attributed to the fact that the foundation is not rectangular, that the pile separation is not constant and that the top soil layers and the bedrock are not homogeneous.

The dynamic soil stiffness of the massless, rigid pile cap is added to the FE model using constraint equations, imposing a rigid body displacement to the base of the pile cap.

Figure 8 shows the displacement of the concentrated mass in the direction of the loading. The resonance related to the first bending mode occurs at a frequency of $11.7 \mathrm{~Hz}$. The increase of the frequency with respect to the model in with a flexible pile cap $(11.2 \mathrm{~Hz})$ is due to the assumption of a rigid pile cap, resulting in a higher dynamic soil stiffness. 


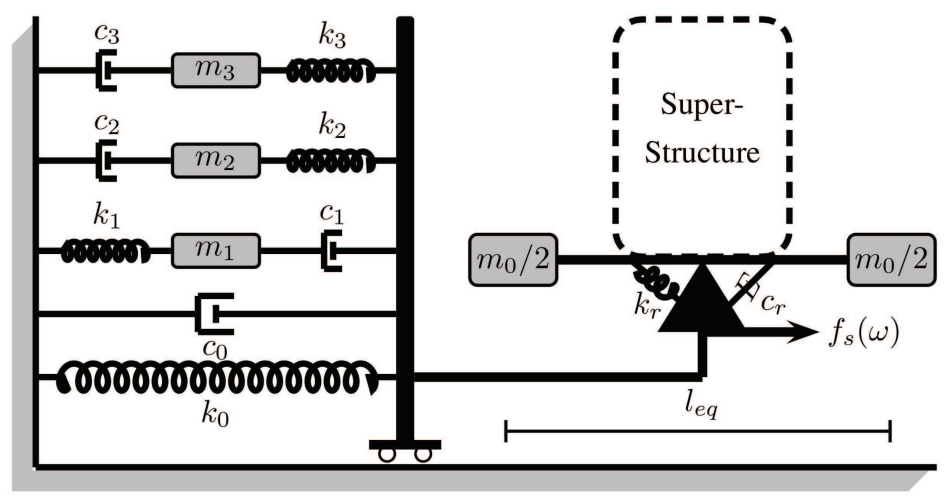

Figure 11: Lumped parameter model for the soil, consisting of a set of masses, springs and dampers [8].

Figure 8 also shows the response as computed with the dynamic soil stiffness from the simplified pile cap model. Since the simplified pile cap model overestimates the dynamic stiffness of the pile group, the corresponding resonance is located at a higher frequency of about $13 \mathrm{~Hz}$. The damping coefficient is underestimated, resulting in a larger response at resonance.

\section{CONCLUSIONS}

In this paper, the dynamic behavior of a telescope pier of an astrophysical laboratory in the Sierra de Javalambre, Teruel (Spain), has been considered.

In order to quantify the effects of dynamic soil-structure interaction, a coupled FE-BE model of the telescope pier on the pile foundation embedded in the soil has been employed. The telescope pier, the foundation cap, the micro-piles and a cylindrical soil volume have been meshed with finite elements. The surrounding layered halfspace has been modelled with boundary elements.

A first analysis that disregards dynamic soil-structure interaction has been performed, where the telescope pier is fixed at its base. The response of the telescope, loaded by a harmonic point load at the top, is dominated by the bending modes of the telescope pier. The first eigenfrequency of the telescope pier equals $14.28 \mathrm{~Hz}$.

A coupled FE-BE model is next used to compute the response of the telescope pier, fully accounting for dynamic soil-stucture interaction. The response of the telescope, loaded by a harmonic point load at the top, is dominated by a resonance peak corresponding to the bending mode of the telescope pier. Due to the effect of dynamic soil-structure interaction, the peak occurs at $11.2 \mathrm{~Hz}$. This demonstrates that the effect of dynamic soil-structure interaction is significant.

A simplified approach is next used where the FE model of the telescope pier is coupled to the pile cap impedance of a rigid pile cap, accounting for dynamic soil-structure interaction in a simplified way. The resulting foundation stiffness and damping coefficients have been validated by means of impedance curves for pile groups, as published in the literature [8]. The dynamic soil stiffness of the massless, rigid pile cap is added to the FE model using constraint equations, imposing a rigid body displacement to the base of the pile cap. Due to the assumption of a rigid pile cap, the dynamic soil stiffness is higher than in the case of a flexible pile cap, and the resonance related to the first bending mode of the telescope pier occurs at $11.7 \mathrm{~Hz}$. This demonstrates that the flexibility of the pile cap has only a minor effect on the resonance frequency of the telescope pier. 


\section{ACKNOWLEDGEMENTS}

The results presented in this paper have been obtained in collaboration with the Universitat Politécnica de València in commission of TORRESCAMARA. The first author is a postdoctoral fellow of the Research Foundation - Flanders (FWO). All financial support is hereby gratefully acknowledged.

\section{REFERENCES}

[1] R.J. Apsel and J.E. Luco. Impedance functions for foundations embedded in a layered medium: an integral equation approach. Earthquake Engineering and Structural Dynamics, 15:213-231, 1987.

[2] B.G.H. Consulting. Reconocimiento geofísico básico mediante sísmica de refracción, tomografía eléctrica, down-hole, cross-hole y sondeo eléctrico vertical (SEV). Observatorio Astrifísico del Pico del Buitre. Technical report, B.G.H., 2009.

[3] R. Dobry and G. Gazetas. Simple method for dynamic stiffness and damping of floating pile groups. Géotechnique, 38:557-574, 1988.

[4] D. Dooms, G. De Roeck, G. Degrande, and S. François. Een interactieve en adaptieve toepassing voor de statische en dynamische analyse van structuren (StaBIL). Technical Report BWM-2009-21, Department of Civil Engineering, KU Leuven, October 2009.

[5] S. François, M. Schevenels, and G. Degrande. BEMFUN: MATLAB toolbox for boundary elements in elastodynamics. Version 2.1 Build 16. User's guide BWM-2009-26, Department of Civil Engineering, KU Leuven, December 2009.

[6] Geodeser. Estudio geológico-geotécnico. Observatorio Astrifísico del Pico del Buitre. Technical report, Geodeser, 2009.

[7] J.-G. Sieffert and F. Cevaer. Handbook of impedance functions. Surface foundations. Ouest Editions, Presses Académiques, Nantes, 1992.

[8] R. Taherzadeh, D. Clouteau, and R. Cottereau. Simple formulas for the dynamic stiffness of pile groups. Earthquake Engineering and Structural Dynamics, 38(15):1665-1685, 2009. 